\title{
The Performance of Controlling Cannon Barrel Position on the Moving Platform Using Neural Network Control and Sliding Mode Control
}

\author{
Wiwik Wiharti, Santi Anggraini, and Ihsan Lumasa Rimra, Member, IACSIT
}

\begin{abstract}
One of the gunboat weapons that need to stay stable is the cannon. Its unbalance position that caused by pitch and roll disturbance will influence the target accuracy, target detection, tracking system, object identification and the ability to counter the threat. In order to determine this disturbance, the balancing control on the movement platform can be solved by using neural network control and sliding mode control methods. To make an approach, the cannon movement system can be modeled in training and elevation movements and the disturbances are modeled through pitch and roll mechanisms. The variations in obtained parameters of training and elevation (moment of inertia) are the non-linearity result of the moving cannon. The system is simulated to verify the error in the controller's output processed using the neural network coordination system control and sliding mode control. The learning process in the neural network is made using back propagation method in order to get the weight value at the different disturbances which their results are given in the simulation of coordination models. On the other hand, the free chattering of sliding mode control is implemented in order to make the movement of training and elevation can be controlled for having the desired angle position in the disturbance of pitch and roll. This paper is based on the study to compare the performance of neural network control and sliding mode control on the moving platform.
\end{abstract}

Index Terms - Cannon barrel, elevation and training, neural network control, pitch and roll, sliding mode control.

\section{INTRODUCTION}

One of the gunboat weapons on the warship that plays an important role is the cannon. Discovering and determining a stable position of the cannon in a moving platform is hard to obtain since its position on the warship is disposed unbalance. This is the effect of water wave that makes the warship move up and down and swing to the left and right which is also known as pitch and roll as in [1]-[5]. As a consequence of the disturbances, it influences target accuracy, target detection, tracking system, object identification and the ability to counter the threat. Hence, it is very important so as to make the cannon barrel can be

Manuscript received August 14, 2014; revised October 8, 2014. This work was supported in part by the Directorate General of Higher Education of Indonesian Republic through State Polytechnic of Padang.

Wiwik Wiharti is with the Department of Electronics Engineering, State Polytechnic of Padang, Indonesia (e-mail: wiwik@polinpdg.ac.id).

Santi Anggraini is with the Department of Electronics Engineering, Electronic Engineering Polytechnic Institute of Surabaya, Indonesia (e-mail: santi@pens.ac.id).

Ihsan Lumasa Rimra is with the Department of Telecommunication Engineering, State Polytechnic of Padang, Indonesia (e-mail: rimra@polinpdg.ac.id). adaptable to the environment for shooting the exact point. A correct estimation of a target by using a calculation of the flying period of the cannonball on the moving target and by adjusting position and speed of warship's cannon has been addressed as in [6]. The cannon moves and changes its position when it detects a target. It follows target movements in the form of training and elevation.

The purpose of the paper is to briefly characterize the accomplishment of two control systems to manage the cannon barrel position within a moving platform as the effect of pitch and roll in the form of water wave. The methods of control system implemented in the research are Neural Network Control and Sliding Mode Control. Both methods must be able to control the movement of training and elevation so as the cannon movement can reach the expected angle to shoot. It is obtained through a development of a plant as a prototype of the cannon in order to make the motion of training and elevation to create the target angle based on set point. The disturbances on the moving platform can be minimized so as to make the cannon more accurate and stable to aim the target.

This paper is organized as follows. Section II describes appropriate references showing the previous research related to cannon development. In addition, two control methods will be discussed to make it applicable to manage the motion of the cannon. Section III shows the proposed system and plant identification. In the section IV, we take emphasis and analyze the technical implementation of our work using Neural Network Control (NNC) and Sliding Mode Control (SMC). The methods are considered to determine the disturbances of pitch and roll on the training and elevation movements. Finally, we put forward the conclusion in Section V.

\section{RELATED WORKS}

Basically, the equipped cannon with the controller works by managing the direction of the barrel (elevation) and the cannon body (training) as in [6] that represents data communication between the cannon and controller as shown in Fig. 1. Each part has two synchronous motors which are the transmitter synchronous motor and receiver synchronous motor as in [7]. These synchronous motors provided data communication when the cannon moves to make training and elevation movements. In addition, the cannon itself has two main parts which are the main frame and body gun. The main frame called arm consists of a circuit of mechanical links connected by a joint function as the controller. 


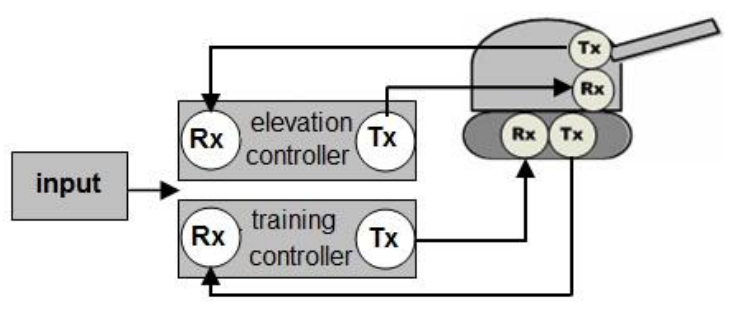

Fig. 1. Data communication on the automatic cannon.

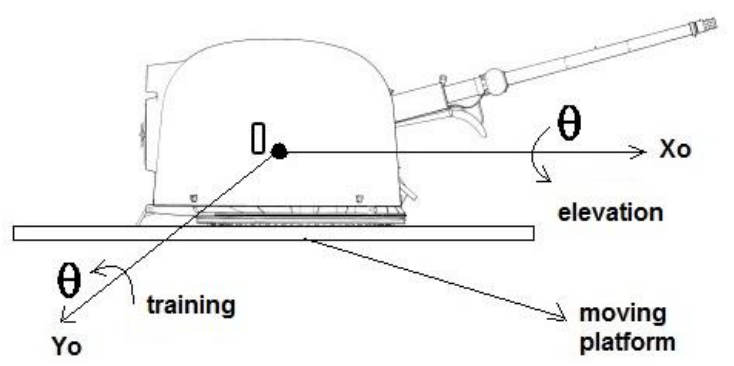

Fig. 2. Cannon in a moving platform.

When error exists in the angle of training and elevation, each transmitter synchronous motor on the cannon sends the error messages to its receiver synchronous motor as the feedback data to make the training and elevation function on the controller. Furthermore, the feedback data is processed by the controller and sent to each transmitter synchronous motor to order the main frame in the cannon to provide the training and elevation function. It is ended when the expected angle position is reached without error messages.

The elevation movement of the cannon is a vertical motion of its arm. On the other hand, the training movement is a horizontal motion of the cannon swinging to the left and right against the cannon body as shown in Fig. 2. $\theta$ in Fig. 2 presents the elevation angle.

\section{A. Neural Network Control}

The NNC method is implemented through a plant system produced by a dynamic system. It is applied to generate the cannon training and elevation using pitch and roll disturbances on the moving platform as in [8]. Basically, the movement of the cannon elevation is the changes of inertia moment influencing the rotation of the motor training as in [9]. This inertia moment variable is the representation of cannon's training and elevation that can be solved using the NNC method. A stable position of the cannon on the warship is effected by the warship movement and the ocean wave. This has the same concept as the stability of a robot arm implemented using the neural network method as in [10]. Robot as an agent must act based on the environment. Hence, a robot must have the ability to learn and to evolve with the dynamic environment as in [11].

\section{B. Sliding Mode Control}

Sliding Mode Control (SMC) is one of the controlling methods with the ability to taking into account the changes affecting the system without influencing the system performance. It provides a systematic approach to adjust stability and to trace the system achievement with a wide variety of models [12]. A structure of an SMC consists of two parts. One part is used to fix error signal by aiming it to an expected path. Another part is applied to maintain the signal on the path.

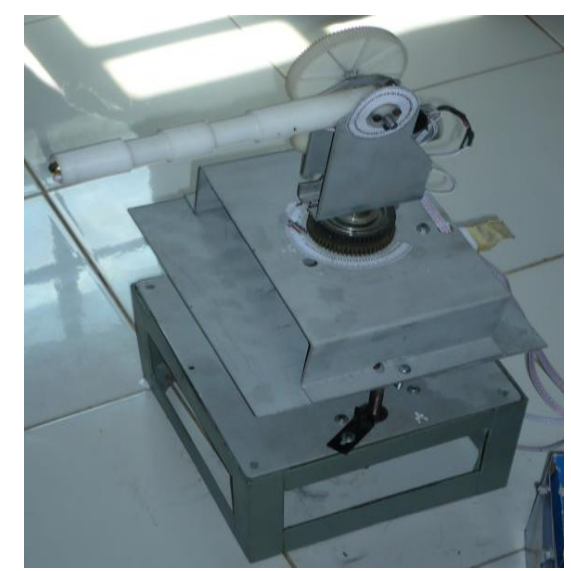

Fig. 3. Cannon prototype.

\section{Plant IDENTIFICATION}

A cannon prototype with training and elevation movement is implemented as a plant as can be seen in Fig. 3. To perform an expected controller design and response, the plant needs to be identified so as to get the mathematical transfer function of the training and elevation movement.

To determine the structure model of the plant in managing a cannon barrel position, the training and elevation movement is made into a second order system. It is implemented in order to decide the type of controller responses that is used for controller parameters of the expected results. In this research, the approach model of ARMA (Auto Regressive Moving Average) is selected to achieve a mathematical model of the training and elevation movement. By using a sampling time of 0.1 second for training and elevation movements, the obtained transfer functions are as follows:

- Training movement

$$
G_{\text {training }}(s)=\frac{-0.1744 s+2.986}{s^{2}+10.26 s+0.0189}
$$

Error norm $=5.7121$

- Elevation movement

$$
G_{\text {elevation }(s)}=\frac{-0.4891 s+7.39}{s^{2}+20.54 s+2.86}
$$

Error norm $=4.1233$

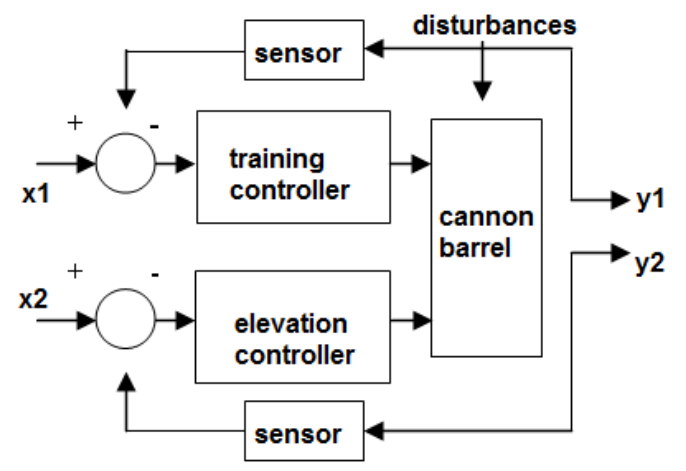

Fig. 4. Diagram of cannon controller.

Fig. 4 shows the block diagram of the cannon controller 
implemented for the research. $x_{1}$ and $x_{2}$ present the input of training and elevation movement respectively. On the other side, $y_{1}$ and $y_{2}$ show the output of training and elevation movement subsequently. Disturbances come from a moving platform that causes the motion of pitch and roll.

\section{A. Neural Network Control}

The learning process implemented in NNC is the supervised learning with back propagation algorithm. It consists of a feed forward process, back propagation and weight modification. It then continues to provide the start of learning algorithm of the controller using the input of the sinusoidal signal. The first learning is applied before the controller is implemented in the real system. Its objective is to determine whether the controller can be used to see the responses.

A design of cannon kinematics system with training and elevation movement is performed by assuming the rotation on the axis of $x, y$ and $z$ and the coordination of movements. The Euler rotation concept expresses 3 parameters in the form of $x, y$ and $z$ through a rotation matrix. Coordinate directions are represented using the right hand coordinate system and the direction of rotation is represented using the right hand rule.

Rotation against the $x$ axis (pitch):

$$
\begin{gathered}
{\left[\begin{array}{l}
x_{1} \\
y_{1} \\
z_{1}
\end{array}\right]=\left[\begin{array}{ccc}
1 & 0 & 0 \\
0 & \cos & -\sin \\
0 & \sin & \cos
\end{array}\right]\left[\begin{array}{l}
x_{0} \\
y_{0} \\
z_{0}
\end{array}\right]} \\
x_{1}=x_{0} \\
y_{1}=y_{0} \cos -z_{0} \sin \\
z_{1}=y_{0} \sin +z_{0} \cos
\end{gathered}
$$

Rotation against the $y$ axis (roll):

$$
\begin{gathered}
{\left[\begin{array}{l}
x_{1} \\
y_{1} \\
z_{1}
\end{array}\right]=\left[\begin{array}{ccc}
\cos & 0 & \sin \\
0 & 1 & 0 \\
-\sin & 0 & \cos
\end{array}\right]\left[\begin{array}{l}
x_{0} \\
y_{0} \\
z_{0}
\end{array}\right]} \\
x_{1}=x_{0} \cos +z_{0} \sin \\
y_{1}=y_{0} \\
z_{1}=-x_{0} \sin +z_{0} \cos
\end{gathered}
$$

Rotation against the $z$ axis (yaw):

$$
\begin{gathered}
{\left[\begin{array}{l}
x_{1} \\
y_{1} \\
z_{1}
\end{array}\right]=\left[\begin{array}{ccc}
\cos & -\sin & 0 \\
\sin & \cos & 0 \\
0 & 0 & 1
\end{array}\right]\left[\begin{array}{l}
x_{0} \\
y_{0} \\
z_{0}
\end{array}\right]} \\
x_{1}=x_{0} \cos -y_{0} \sin \\
y_{1}=x_{0} \sin +y_{0} \cos \\
z_{1}=z_{0}
\end{gathered}
$$

\section{B. Sliding Mode Control}

The SMC without coordination is implemented in the plant controller on the moving platform. It implements the following mathematical model to obtain the training and elevation movements:

- Model of training movement in the state space

$$
\begin{gathered}
{\left[\begin{array}{l}
\dot{x_{1}} \\
\dot{x_{2}}
\end{array}\right]=\left[\begin{array}{cc}
-10.26 & -0.0189 \\
1 & 0
\end{array}\right]\left[\begin{array}{l}
x_{1} \\
x_{2}
\end{array}\right]+\left[\begin{array}{l}
1 \\
0
\end{array}\right] u} \\
y=\left[\begin{array}{ll}
-0.1744 & 2.986
\end{array}\right]\left[\begin{array}{l}
x_{1} \\
x_{2}
\end{array}\right]
\end{gathered}
$$

A sliding surface $(S)$ function is required to guarantee that the surface discontinuity $(S=0)$ can be reached at finite time.

$$
\dot{S}=-49.25 x_{1}-0.09 x_{2}+4.87 u+\lambda \tilde{x}
$$

The control signal $(u)$ is defined as follow:

$$
u=10.1 x_{1}+0.02 x_{2}-0.21 \lambda \tilde{x}-k \operatorname{sgn}(S)
$$

Switching control function $u_{N}=-k \operatorname{sgn}(S)$ causes a chattering effect. It can be eliminated by smoothing the control discontinuity at the boundary layer.

- Model of elevation movement in the state space

$$
\begin{aligned}
{\left[\begin{array}{l}
\dot{x_{1}} \\
\dot{x_{2}}
\end{array}\right] } & =\left[\begin{array}{cc}
-20.54 & -2.86 \\
1 & 0
\end{array}\right]\left[\begin{array}{l}
x_{1} \\
x_{2}
\end{array}\right]+\left[\begin{array}{l}
1 \\
0
\end{array}\right] u \\
y & =\left[\begin{array}{ll}
-0.1744 & 2.986
\end{array}\right]\left[\begin{array}{l}
x_{1} \\
x_{2}
\end{array}\right]
\end{aligned}
$$

The sliding surface $(S)$ and control signal $(u)$ function of the elevation movement are described as follows:

$$
\begin{aligned}
& \dot{S}=-356.82 x_{1}-49.88 x_{2}+16.95 u+\lambda \dot{\tilde{x}} \\
& u=21.05 x_{1}+2.94 x_{2}-0.059 \lambda \dot{\tilde{x}}-k \operatorname{sgn}(S)
\end{aligned}
$$

The chattering effect also happens on the elevation movement with the same solution as described above.

\section{RESUlTS}

The implementation of mathematical model is used to determine the performance of the open loop system without controller by providing step signal tests $70^{\circ}$ (for training) and $50^{\circ}$ (for elevation). Fig. 5 shows the open loop responses.

\section{A. Neural Network Control}

An initial learning is started by assigning the input of a sinus signal (amplitude $=1$ and frequency $=0.1 \mathrm{rad} / \mathrm{s}$ ), learning rate parameter $=0.000005$ and a random value of initial weight. A consistency in controller design and velocity is affecting the learning rate results to reach a time set point. Table I presents the learning results of training and elevation 
movements using $\lambda=0.9$. Fig. 6 and Fig. 7 respectively show the consistency result of training and elevation movements.

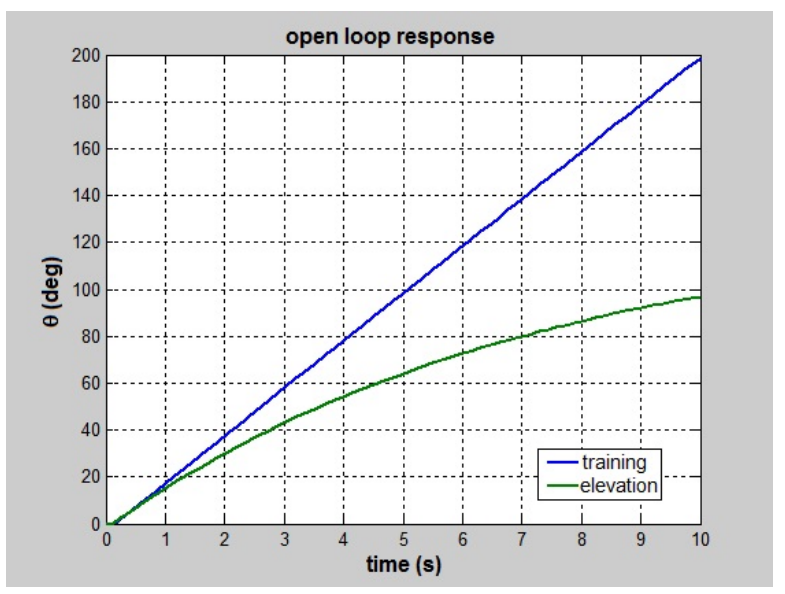

Fig. 5. Open loop response training and elevation movements.

TABLE I: A SUCCEED PARAMETER OF LEARNING WITH $\lambda=0.9$

\begin{tabular}{cc}
\hline \hline Parameter & Value \\
\hline input & 4 \\
hidden & 3 \\
output & 1 \\
$\alpha$ & 0.0000005 \\
$\lambda$ & 0.9 \\
epoch & $1: 10$ \\
\hline \hline
\end{tabular}

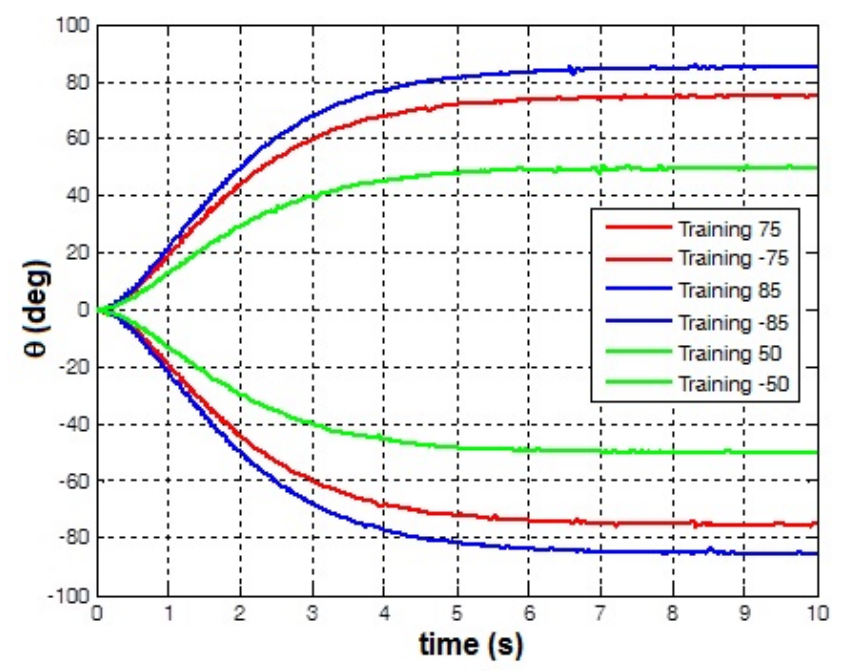

Fig. 6. Consistency result of training movement.

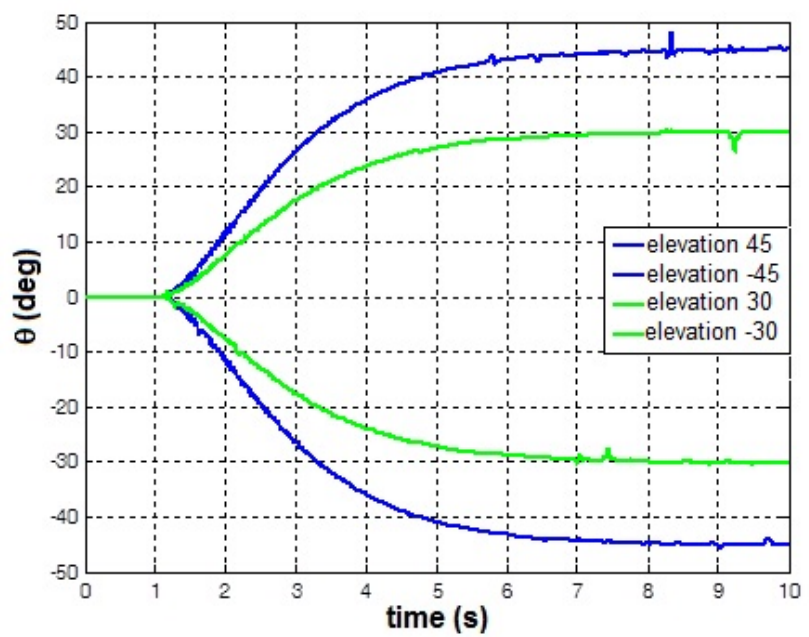

Fig. 7. Consistency result of elevation movement.
Without disturbances, the results of coordination responses on training and elevation movements are $97^{\circ} / \mathrm{sec}$ for the training and $31 \%$ sec for the elevation. Providing disturbances on the system using pitch and roll are the next steps of the coordination system implementation. An example shown in Fig. 8 provides the values for calculations in which the platform will be rotated using pitch $=5^{\circ}$ and roll= $20^{\circ}$.

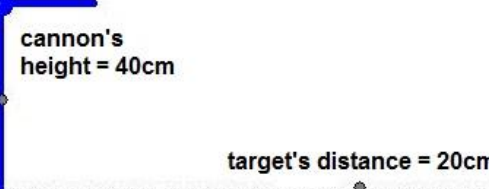

Fig. 8. An example of cannon's design values.

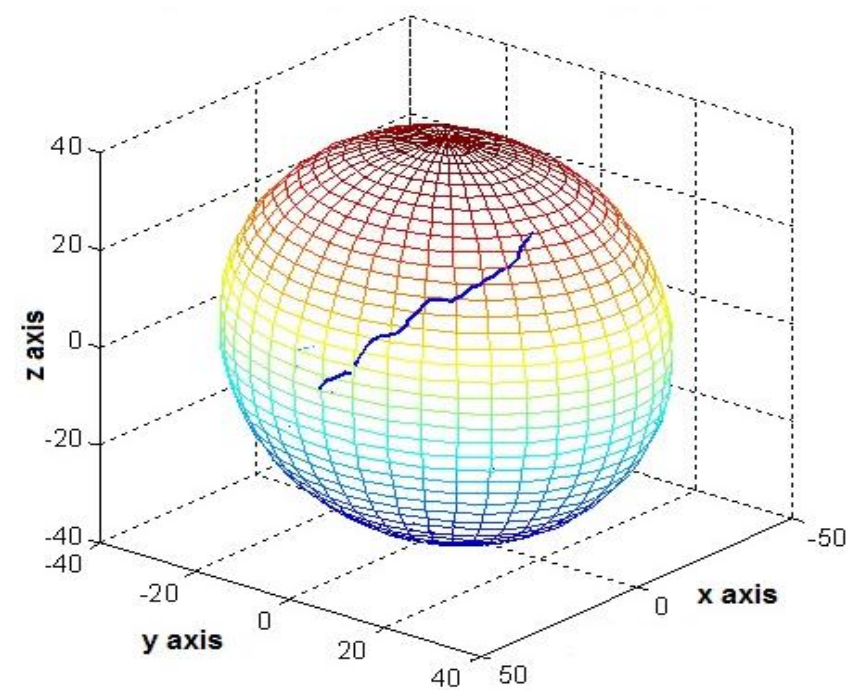

Fig. 9. Three dimensional of coordination responses.

Using Cartesian coordinate, $P_{\mathrm{o}}(0,20,40)$ is the initial position of the cannon. A displacement position from $P_{0}\left(x_{0}\right.$, $\left.y_{0}, z_{0}\right)$ to $P_{1}\left(x_{1}, y_{1}, z_{1}\right)$ is caused by roll disturbances $\theta$ to the plant. Equation (4) produces the coordinate position of $P_{1}\left(x_{1}\right.$, $\left.y_{1}, z_{1}\right)=P_{1}(13.67,20,37.59)$ based on values $P_{0}=(0,20,40)$ and $\theta=20^{\circ}$.

$$
P_{1}=\left[\begin{array}{l}
x_{1} \\
y_{1} \\
z_{1}
\end{array}\right]=\left[\begin{array}{ccc}
\operatorname{Cos} 20 & 0 & \operatorname{Sin} 20 \\
0 & 1 & 0 \\
-\operatorname{Sin} 20 & 0 & \operatorname{Cos} 20
\end{array}\right]\left[\begin{array}{c}
0 \\
20 \\
40
\end{array}\right]=\left[\begin{array}{c}
40 \operatorname{Sin} 20 \\
20 \\
40 \operatorname{Cos} 20
\end{array}\right]=\left[\begin{array}{c}
13.67 \\
20 \\
37.59
\end{array}\right]
$$

Fig. 9 shows the result of three dimensional coordination responses on some calculations referring to (3), (4) and (5). It is based on pitch and roll disturbances on training and elevation movements against the axis of $x, y$ and $z$.

\section{B. Sliding Mode Control}

A controller is needed to maintain a stable and the performance of a system. The expected performances of the system are without chattering, a quick rise time $(<2 \mathrm{sec})$ and steady state error $=0$. The first implementation of SMC, the system is assigned a roll disturbance using a sinus signal with the amplitudo of $1^{0}$ and frequency of $1 \mathrm{rad} / \mathrm{s}$. Since the ouput signal has smally changed for about $0.03^{\circ}$, it does not influence the system. It stays in sliding mode and the controller takes into account disturbances. The control signal 
(u) is gently osilated by disturbances, however, it achieves its steady state. Fig. 10 presents a response of a training movement with roll disturbances. Further, the following system's specifications provide result responses.

$$
\begin{aligned}
& \text { Steady state }=70.01^{\circ} \\
& \text { Rise time }=1.49 \mathrm{sec}
\end{aligned}
$$$$
\text { Settling time }=1.86 \mathrm{sec}
$$

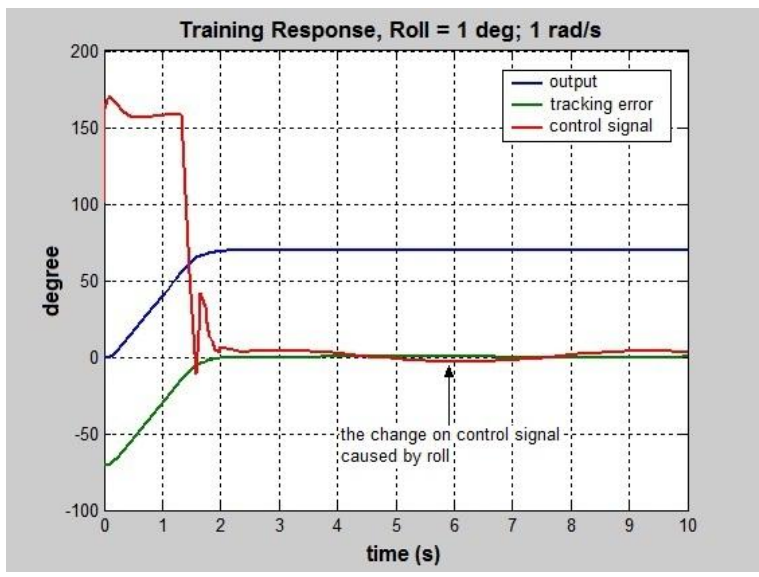

Fig. 10. Training movement's response with roll disturbance.

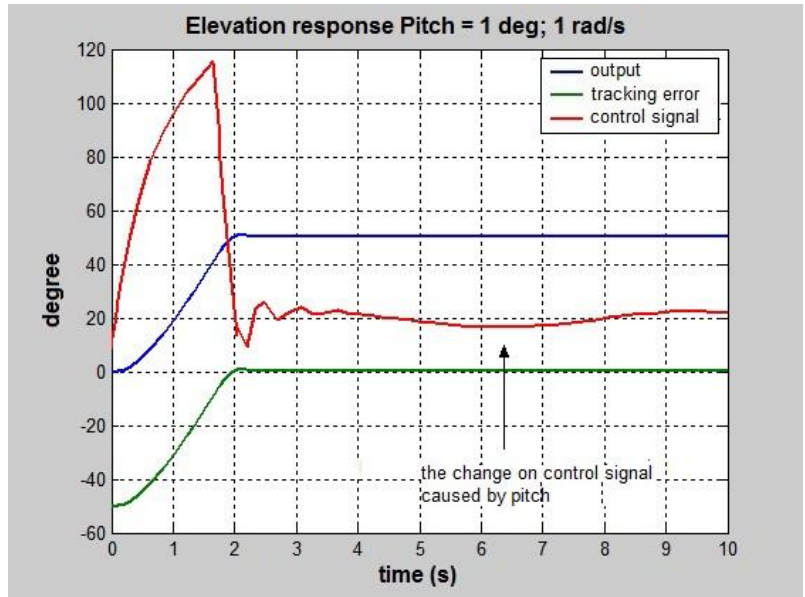

Fig. 11. Elevation movement's response with pitch disturbance.

The same mechanism of the sinus signal is applied for the elevation movement with pitch disturbances. The result is shown in Fig. 11. Result responses is provided in the following specifications:

$$
\begin{gathered}
\text { Overshoot }=0.57^{0} \\
\text { Steady state }=50.2^{\circ} \\
\text { Rise time }=1.6861 \mathrm{sec}
\end{gathered}
$$

Settling time $=1.8619 \mathrm{sec}$

The displacement positions of the elevation caused by pitch and overshoot are very small. It is not affecting the system. The performance of specifications is compatible to design characteristics.

Fig. 12 and Fig. 13 respectively show that disturbances are not influencing the system to reach the set point. Pitch and roll disturbances are not affecting in sliding mode system. The time needed by training movements to achieve the set point is $1.04 \mathrm{sec}$. However, the time acquired to reach elevation movements is $2 \mathrm{sec}$.

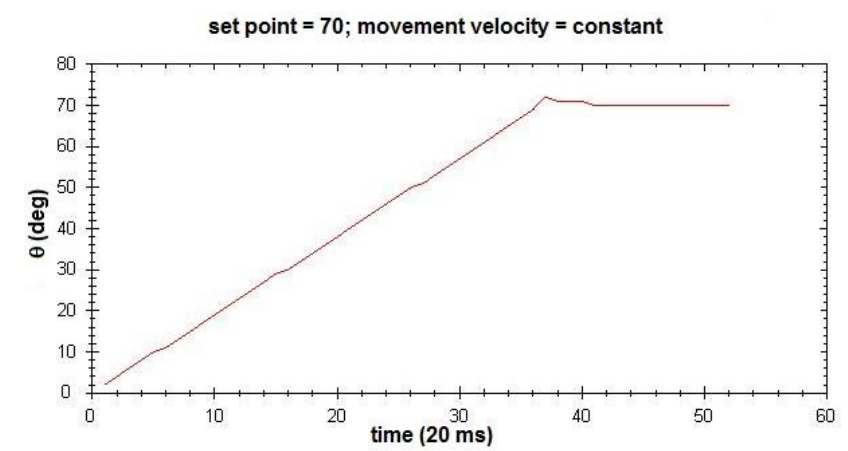

Fig. 12. Training movement's response with roll $=5^{\circ}$, velocity $=$ constant.

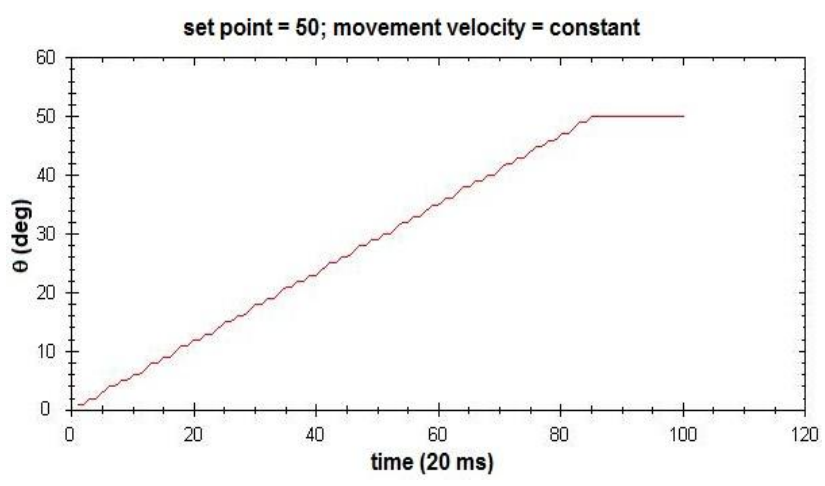

Fig. 13. Elevation movement's response with pitch $=5^{\circ}$, velocity $=$ constant.

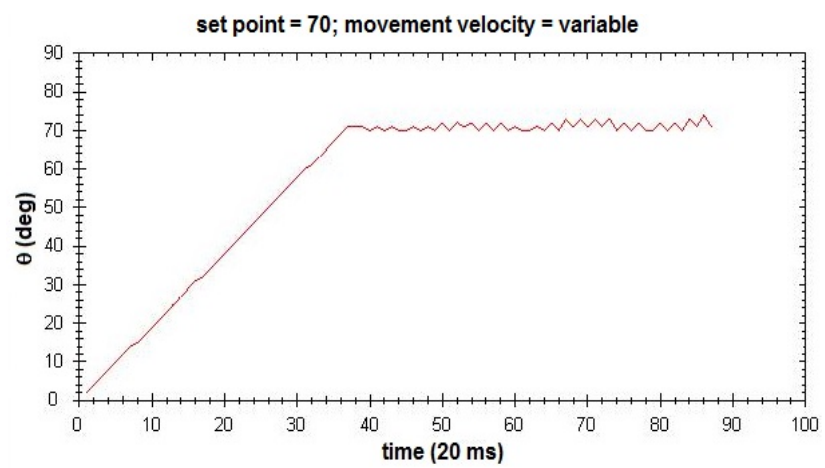

Fig. 14. Training movement's response with roll $=5^{\circ}$, velocity $=$ varies.

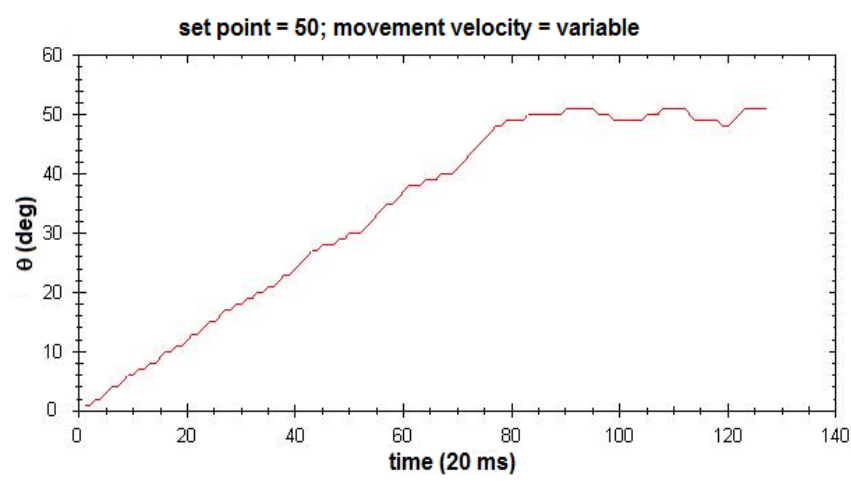

Fig. 15. Elevation movement's response with pitch $=5^{\circ}$, velocity $=$ varies.

Further, when the velocity of disturbances are changed, the controller puts back the cannon's barrel position based on its set point. The requirement time for training movements to reach the set point is $1.8 \mathrm{sec}$. On the other hand, $2.6 \mathrm{sec}$ is recquired by elevation movements to achieve its set point. The time to reach the set point on elevation movements is longer comparing to the previous results. However, it still can be tolerated by the system since the steady state condition in the system requirement is performed. The results of the variation in disturbances are shown in Fig. 14 and Fig. 15. 


\section{CONCLUSION}

This work shows that the cannon barrel position on the moving platform can be controlled in order to aim the exact target. In order to determine this disturbance caused by pitch and roll, the balancing control on the movement platform can be solved by using neural network control and sliding mode control methods. By modeling the system in training and elevation movements, the NNC and MNC methods can verify the error in the controller's output processed. The coordination system on NNC may put back the cannon to its position. On the other hand, the SMC controller implements the restoration method by recovering the cannon barrel position based on its set point. Nevertheless, both methods cannot be compared directly since the methods use different approaches to determine disturbances.

\section{ACKNOWLEDGMENT}

The authors wish to thank Rusdhianto EAK, Ali Fatoni and Imam Arifin for valuable guidance and feedback during research implementation.

\section{REFERENCES}

[1] C. Siegenthaler, C. Pradalier, F. Gunther, G. Hitz, and R. Siegwart, "System integration and fin trajectory design for a robotic sea-turtle," in Proc. IEEE International Conference on Intelligent Robots and Systems, November 2013, pp. 3790-3795.

[2] T. Matsumoto et al., "Evaluation of body response to artificial ship movement by visual and motion platform," World Automation Congress (WAC), pp. 1-6, September 2010.

[3] K. Murai, Y. Hayashi, T. Okazaki, and S. Inokuchi, "Study on body response to artificial ship rolling and pitching," in Proc. IEEE International Conference on Systems Man and Cybernetics (SMC), October 2010, pp. 3265-3269.

[4] P. Edgar and S. M. Smith, "An experimental self-motion study of the ocean explorer AUV in controlled sea states," IEEE Journal of Oceanic Engineering, vol. 23, pp. 274-284, July 1998.

[5] R. V. Bostelman and J. S. Albus, "Stability of an underwater work platform suspended from an unstable reference," in Proc. OCEANS '93. Engineering in Harmony with Ocean, October 1993, vol. 2, pp. II321-II325.

[6] J. H. Hong, S. Park, C. K. Ryoo, and Y. D. Song, "Aiming accuracy improvement of a warship cannon in consideration of ocean environments," in Proc. SICE Annual Conference, August 2012, pp. 1619-1624.

[7] K. Seki, M. Watada, S. Torii, and D. Ebihara, "Discontinuous arrangement of long stator linear synchronous motor for transportation system," in Proc. International Conference on Power Electronics and Drive Systems, May 1997, vol. 2, pp. 697-702.

[8] H. Hemami, K. Barin, and Y. C. Pai, "Quantitative analysis of the ankle strategy under translational platform disturbance," IEEE Transactions on Neural Systems and Rehabilitation Engineering, vol. 14, pp. 470-480, December 2006.

[9] C. L. Lin, H. Y. Jan, T. S. Hwang, and R. C. Tsai, "Control design for a mixed rotary and linear motors based manipulator," in Proc.
International Conference on Advanced Intelligent Mechatronics, July 2003, vol. 2, pp. 1298-1303.

[10] K. V. Lakshmi and N. Mashuq, "An adaptive Neuro-Fuzzy control approach for motion control of a robot arm," in Proc. International Conference on Informatics, Electronics \& Vision, May 2012, pp. 832-836.

[11] K. O. Chin and J. Teo. "Multi-objective evolution and hinton analysis of minimal neural control structures in an autonomous wheeled robot for RF-localization behaviors," in Proc. International Conference on Intelligent and Advanced Systems, June 2010, pp. 1-6.

[12] R. Furlan, F. A. Cuzzola, and T. Parisini, "Friction compensation in the interstand looper of hot strip mills: A sliding-mode control approach," in Proc. the 11th Mining, Mineral and Metal (MMM) Symposium, Special Issue on Advanced Control Methodologies for Mining, Mineral and Metal (MMM) Processing Industries, February 2008, vol. 16, pp. 214-224.

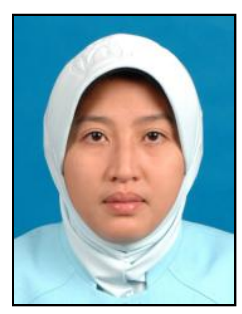

Wiwik Wiharti was born in Surabaya, Indonesia in 1977. She got the bachelor degree of instrumentation engineering in 2002 and master degree of control system engineering in 2010 from the Sepuluh Nopember Institute of Technology.

Her research is focused on developing of control system, sensor network and embedded system. She is also a lecturer in State Polytechnic of Padang at the Electronics Engineering Department.

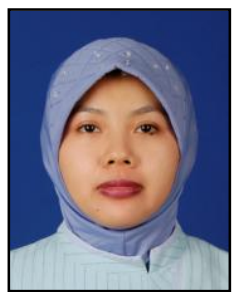

Santi Anggraini was born in Jakarta, Indonesia in 1976. She got the bachelor degree of control engineering in 2002 from Gajah Mada University. Then she obtained her master degree in control system engineering in 2010 from the Sepuluh Nopember Institute of Technology.

Her research interest is in electrical engineering. She takes part in the application of embedded system in electronic control system research. She works as a lecturer in Electronic Engineering Polytechnic Institute of Surabaya, Indonesia.

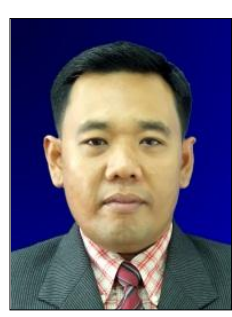

Ihsan Lumasa Rimra was born in Padang, Indonesia, in 1978. After completing his bachelor degree on telecommunication engineering in 2003 from Electronic Engineering Polytechnic Institute of Surabaya Indonesia, he received his MSc degree in design and engineering of convergent networks from Telecom Bretagne in Rennes, France in 2011. He also took part in a research project on IPv6 end to end implementation in the Research and Development Department of France Telecom, France.

He immediately incorporates to the Computer Networking Laboratory State Polytechnic of Padang to take part in several research projects regarding IPv6, Internet access network and wireless communication. he is also a lecturer of the computer networking, data communication and internet technology subject at State Polytechnic of Padang, Indonesia. 